NASA Technical Memorandum 102278

\title{
Seasonal LAI in Slash Pine Estimated with Landsat TM
}

Paul J. Curran, Jennifer L. Dungan, and Henry L. Gholz

May 1990

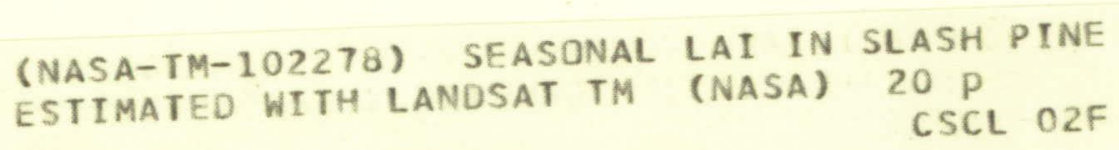


NASA Technical Memorandum 102278

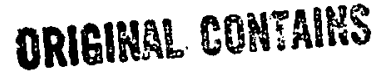

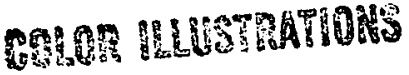

\section{Seasonal LAl in Slash Pine Estimated with Landsat TM}

Paul J. Curran, University College of Swansea, Swansea, United Kingdom Jennifer L. Dungan, TGS Technology, Inc., Ames Research Center, Moffett Field, California Henry L. Gholz, University of Florida, Gainesville, Florida

May 1990

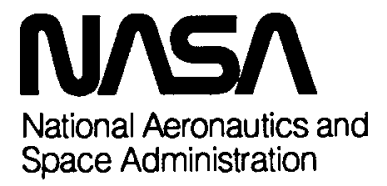




\section{SUMMARY}

The leaf area index (LAI, total area of leaves per unit area of ground) of most forest canopies varies throughout the year, yet for logistical reasons it is difficult to estimate anything more detailed than a seasonal maximum LAI. To determine if remotely sensed data can be used to estimate LAI seasonally, field measurements of LAI were compared to normalized difference vegetation index (NDVI) values, derived using Landsat Thematic Mapper (TM) data, for 16 fertilized and control slash pine plots on three dates.

Linear relationships existed between NDVI and LAI with $R^{2}$ values of $0.35,0.75$, and 0.86 for February 1988, September 1988, and March 1989, respectively. This is the first reported study in which NDVI is related to forest LAI recorded during the month of sensor overpass.

Predictive relationships based on data from eight of the plots were used to estimate the LAI of the other eight plots with a root-mean-square error of $0.74 \mathrm{LAI}$, which is $15.6 \%$ of the mean LAI. This demonstrates the potential use of Landsat TM data for studying seasonal dynamics in forest canopies.

\section{INTRODUCTION}

Accurate estimates of the seasonal dynamics of forest leaf area index (LAI, total area of leaves per unit area of ground) of forests are essential for determining the seasonal exchange of energy and material between the forest canopy and atmosphere. Without seasonal estimates of LAI it is not possible to predict the forest's subtle response to changing environmental conditions (Rook et al., 1985) or to develop seasonally sensitive models of canopy processes (Smolander et al.,1987). However, the destructive measurement of forest LAI throughout the year is arduous, involving the manual enumeration of leaves for representative, and therefore large, areas of forest.

Remotely sensed radiation in near infrared (NIR: 760-900nm) and red (R: 630-690nm) wavebands has the potential for use in estimating forest LAI (Peterson and Running, 1989). In NIR wavelengths, within-leaf scattering is high and therefore reflection from the canopy is high, but in $\mathrm{R}$ wavelengths pigment absorption is high and therefore reflection is low (Curran, 1983; Jensen, 1983). Consequently, LAI is usually related positively to an increase in the difference between NIR and R (Ashcroft et al., 1990, Girard et al., 1990), at least up to the reflectance asymptote of the canopy (Curran, 1985).

The remote sensing of forest LAI has been hampered by the need to measure LAI (or similar measure of foliar mass) with an accuracy adequate for deriving a predictive relationship (Curran and Williamson, 1985). Despite the logistical problems involved, several groups have managed to produce such relationships (e.g., Jensen and Hodgson, 1985; Running et al., 1986; Badhwar et al., 1986a, 1986b; Danson, 1987; Spanner et al., 1990; Running et al., 1989; Sader et al., 1989; Herwitz et al., in press; Spanner et al., in review). For instance, Peterson et al. (1987) reported a correlation coefficient between LAI and NIR/R of 0.83 for forests in the Pacific Northwest, pointing to the potential of this approach. Some of these relationships were made possible by including a very wide range of vegetation types or LAI. Unfortunately, the ground data upon which these reported relationships were based used methods 
of measuring LAI that are inherently unresponsive to seasonal chiange. For example, most were derived using regression relationships between leaf area (or leaf mass) per tree and a seasonally stable tree dimension (e.g., diameter at breast height (dbh)), with both variables collected at various times throughout the growing season and often over different years (e.g., Gholz et al., 1979). Therefore, the application of these relationships, although potentially useful for estimating LAI over large areas for one point in time, cannot be used to study the seasonal LAI of a forest stand.

This paper reports the use of remotely sensed data for estimating seasonal LAI in a stand of slash pine (Pinus elliottii). This work was partially funded by NASA's Earth Sciences Applications Division while Paul Curran held a Senior NRC/NASA Research Associateship at NASA Ames Research Center under a grant from the NASA Life Sciences Division and by NSF Ecosystem Program Grant number 8106678. The stands for this research were used with the permission of the Jefferson-Smurfit Co. The authors thank Wendell Cropper Jr., Dave Delgado, Denise Guerin, David Nolletti, and Sherryl Vogel, Department of Forestry, University of Florida, for assistance in the field and the laboratory; Xoan Trinh, NASA Ames Research Center, for assistance with data processing; and Dave Peterson, Mike Spanner, and Vern Vanderbilt, NASA Ames Research Center, for their comments on the manuscript.

\section{Study Site}

The study site is a 23-year-old (in 1988) slash pine plantation in northern Florida, located approximately $20 \mathrm{~km}$ northeast of Gainesville (fig. 1). The site is essentially flat and has a mean elevation of $35 \mathrm{~m}$. The soil is an ultic haplaquod with a low organic matter and nutrient content and a seasonally high water table (USDA, 1954). The mean annual rainfall for the area is $1350 \mathrm{~mm}$ and the mean annual temperature is $21.7^{\circ} \mathrm{C}$ (Gholz et al., 1990). The canopy is open and the understory comprises a shrub cover, dominated by saw palmetto (Serenoa repens) and a sparse cover of grasses and forbs overlying dead

pine needles. The ecology of the area is well documented (Gholz and Fisher, 1982; Gholz et al., 1985a, 1985b, 1986, 1990).

In $1986,1650 \mathrm{~m} \times 50 \mathrm{~m}$ plots were established at the study site (fig. 1). Half of the plots were fertilized (plots 1, 4, 6, 8,10,11,14, and 15) and the other half were controls (plots 2, 3, 5, 7, 9, 12, 13, and 16). Fertilization involved quarterly additions of a complete fertilizer, starting in February 1987 (Gholz et al., 1990). The increase in LAI associated with the fertilization was evident by early 1988 and resulted in a near $40 \%$ increase in LAI by early 1989.

\section{METHODS}

LAI and remotely sensed data were collected for each of the 16 plots. 


\section{LAI Measurements}

The LAI of each plot was determined monthly for three years from mid-1986, with the aim of quantifying the carbon flux in slash pine. The procedures for determining LAI are given in detail in Gholz et al. (1990); here we present a summary of the four methodological stages.

Stage 1: Estimating the biomass per plot for August 1987, 1988, and 1989.

The dbh of all trees in each plot was measured annually and allocated to one of six dbh classes. In August of each year, between 20 and 30 trees were felled in proportion to the number of trees in each dbh class. The branches were divided into two size classes for each $1-\mathrm{m}$ vertical segment of each tree. Dimensional measurements (primary branch length, diameter at the base, foliated length, diameter at the base of live foliage, number of high-order branchlets, and number of foliage clumps) were made for one branch in each size class. The branches were divided into new foliage ( $<1$ year old), old foliage $(>1$ year old), and woody material; dried at $70^{\circ} \mathrm{C}$; and weighed. The foliar biomass was reconstructed for each sample tree by multiplying sample branch dimensions and dry weights from each $1-\mathrm{m}$ vertical segment, and then summing the products for the tree. These biomass estimates per sample tree were then extrapolated to each plot using the dbh classes measured annually.

Stage 2: Determining the growth of new foliage

The lengths of needles on 15 branches from the central four plots (fig. 1) were measured twice monthly in the spring and monthly for the rest of the year. The monthly elongation rates averaged over all canopy positions were expressed as proportions of the maximum for that year. These proportions were then used to adjust the new foliage biomass values from zero at bud-burst, through the August sampling, and on to the maximum in the fall.

Stage 3: Determining the loss of old foliage

Litterfall was collected monthly from five $1-\mathrm{m}^{2}$ traps in each of the plots. The litterfall was separated into needles and woody material and was dried at $70^{\circ} \mathrm{C}$. The dry weight of litter biomass was used to adjust the old foliage biomass values. This was achieved by adding monthly values of litter biomass from bud-burst until August to August old foliage biomass values. Monthly values of litter biomass were subtracted from August old foliage biomass values until the old foliage biomass reached zero in the fall.

\section{Stage 4: Converting from biomass to leaf area}

The relationship between biomass ( $\mathrm{g}$ of dry needles) and leaf area $\left(\mathrm{cm}^{2}\right.$ of fresh needles) was determined using 1072 fascicles sampled in August 1986; 5 fascicles in each age class within the upper, middle, and lower positions of the canopy sampled in October 1986; 20 fascicles from the upper and lower portions of the canopy sampled in 1988 and 1989; and a selection of fresh litterfall. Total fascicle LAI was calculated from needle volumes and lengths using the water-inversion method (Johnson, 1984). This relationship was applied to all biomass estimates and resulted in estimates of new LAI and old LAI. These estimates of LAI were combined to give one estimate of LAI in each plot for each month for three years. These values had a relatively low error of approximately 0.6 LAI (Gholz et al., 1990), so for the remainder of this paper they are referred to as measured LAI. 


\section{Remotely Sensed Measurements}

Remotely sensed data in R and NIR wavebands with a spatial resolution finer than the plot size are available from airborne multispectral scanners, the Systeme Probatoire de l'Observation de la Terre High Resolution Visible (SPOT HRV) scanner and the Landsat Thematic Mapper (TM). The largest historical and likely future record of the study site was provided by the Landsat TM, therefore these data were chosen for analysis.

The images were in digital form with each radiation value representing an area approximately $30 \mathrm{~m} \times 30 \mathrm{~m}$ on the ground. Three images with under $10 \%$ cloud cover were selected from February 26 , 1988 (scene Y5145715305X0), September 21, 1988 (scene Y5166515315X0), and March 16, 1989 (scene Y5184115302X0) (fig. 2). Scenes were purchased with nearest-neighbor geometric correction on a space oblique Mercator projection. Image processing involved two stages: general radiometric and atmospheric correction and specific processing comprising plot location, irradiance normalization, and waveband ratioing and normalization for the effect of solar zenith angle.

Radiometric correction involved converting relative digital numbers (DN) in each waveband to absolute radiance $(\mathrm{L})$ in $\mathrm{mW} \cdot \mathrm{cm}^{-2} \cdot \mu \mathrm{m}^{-1}$ :

$$
\mathrm{L}=\text { gain }(\mathrm{DN}-\text { offset) }
$$

using the gain and offset data provided by the Earth Observation Satellite Company (Clark, 1986).

Atmospheric correction involved suppressing the effect of atmospheric scattering using the modified dark-object subtraction technique of Chavez $(1988,1989)$. First, the minimum radiance of deep lakes in the image was extracted, assuming that without atmospheric scattering the minimum radiance of these features would be zero. Second, a relative power-law scattering model was selected to represent the atmospheric conditions at the time the images were collected, using the guidelines provided by Chavez (1988). This usually varies from the -1 power of the wavelength on moderately clear days to the -0.7 power on hazy days. Using the minimum radiance in the green TM waveband as an arbitrary starting point, the model was applied to radiance in all wavebands. For example, in the September 1988 image, 0.623 and $0.732 \mathrm{~mW} \cdot \mathrm{cm}^{-2} \cdot \mathrm{sr}^{-1} \cdot \mu \mathrm{m}^{-1}$ were subtracted from radiance in the NIR and $\mathrm{R}$ wavebands respectively.

To locate the plots on the images, between 16 and 20 ground control points were collocated on a topographic map and each digital image of the study site. The pixel closest to the center of each plot was identified by triple-triangulation from relevant ground control points and the radiance was extracted. If repeated triangulation located two adjacent pixels for one plot, the mean radiance of the two was used.

To suppress irradiance differences between images, the radiance was normalized by the irradiance. This was accomplished by using the mean radiance of three road intersections in each image as a measure of relative irradiance with which to normalize all of the images to that of February 1988. For example, to ensure that three road intersections in the September 1988 image had a radiance similar to the same road intersections in the February 1988 image, 1.31 and $0.88 \mathrm{~mW} \cdot \mathrm{cm}^{-2} \cdot \mathrm{sr}^{-1} \cdot \mu \mathrm{m}^{-1}$ were subtracted respectively from radiance in the NIR and R wavebands of the September 1988 image. 
Using radiance (L) in NIR and R wavebands, the normalized difference vegetation index (NDVI) was calculated as

$$
\mathrm{NDVI}=\left(\mathrm{L}_{\mathrm{NIR}}-\mathrm{L}_{\mathrm{R}}\right) /\left(\mathrm{L}_{\mathrm{NIR}}+\mathrm{L}_{\mathrm{R}}\right)
$$

Finally, as the NDVI is related negatively to the solar zenith angle (Holben, 1986), it was normalized to a constant solar zenith angle using the relative look-up graph of Singh (1988). This processing yielded one NDVI value per plot, per date.

\section{RESULTS}

The NDVI and LAI for 16 plots on 3 dates are presented in an abbreviated form in table 1 and as scatterplots in figure 3. The increased variability of both NDVI and LAI in September 1988 and March 1989 was attributable to the higher values of both variables on the fertilized plots (table 2).

There was a positive, linear relationship between NDVI and LAI on all three dates, with $\mathrm{R}^{2}$ values of $0.35,0.75$, and 0.86 for February 1988, September 1988, and March 1989, respectively (fig. 3). This

linearity was expected as the reflectance asymptote for conifer canopies is usually reached at LAI values far in excess of those recorded on the study site (Peterson et al., 1987, Herwitz et al., in press). The relationships between NDVI and LAI are visually similar for the three dates (fig. 3). However, the constants and NDVI coefficients differed ( $F$ test) at the 0.95 level of significance. These differences can be attributed to measurement error and probable differences in atmospheric conditions and understory ground cover at the time of image acquisition (Fraser and Kaufman, 1985; Curran and Williamson, 1987; Spanner et al., 1989).

Using data from plots 1 to 8 , three predictive relationships were derived (table 3 ). These relationships were used to estimate the LAI of plots 9 to 16 with a root-mean-square error of $0.74 \mathrm{LAI}$, which is $15.6 \%$ of the mean LAI (fig. 4). Table 4 presents results combined by treatment, showing the mean estimated and measured LAI for fertilized plots 10,11, 14, and 15 and control plots 9, 12, 13, and 16.

\section{DISCUSSION}

The relationships illustrated in figure 4 , in which remotely sensed data are related directly to forest LAI measured during the month of satellite overpass, are the first of their kind to be reported. They demonstrate the potential value of Landsat TM data for estimating seasonal changes in a single forest type by accurately tracking the LAI increase from February 1988 to September 1988 and the decrease from September 1988 to March 1989 (fig. 4, table 4). These relationships were made possible by the existence of monthly ground measurements of LAI; the relatively simple structure and single age of the slash pine plantation; and careful correction of Landsat TM radiance values for the effects of the temporally variable atmosphere, irradiance, and solar angle. 
The NDVI used in this study suppresses waveband-independent effects and enhances wavebanddependent effects. In doing so it masks the individual roles of R and NIR in the NDVI. Researchers have shown that NIR varies little over a wide range of forest LAI while $R$ varies greatly over a wide range of forest LAI (e.g., Peterson et al., 1987). This was also observed in the data for February 1988, as the

coefficients of variation were 0.047 and 0.071 for NIR and R, respectively. However, by September 1988 , the LAI and NIR were higher on the fertilized plots, but the R was similar on the fertilized and control plots. Consequently, the coefficients of variation in September 1988 were 0.088 and 0.047 for NIR and R, respectively, a pattern which remained in March 1989, with coefficients of variation of 0.079 and 0.057 .

The fertilized plots tended to have a higher LAI than the control plots and could be discriminated on the basis of NDVI (fig. 5). This was also visually apparent on false color Landsat TM images (fig. 2). Part of the increase in the total LAI on the fertilized plots was due to an increase in understory LAI (D. Guerin and H. Gholz, unpubl.). However this effect was small. Between 1986 and 1988, the dates for which we have data, the understory LAI increased by approximately $35 \%$ on the control and $65 \%$ on the fertilized plots, while maintaining preexisting patterns in understory coverage between plots. Clearly, the NDVI values may have been inflated relative to the canopy LAI when the canopy LAI was low; field observations indicated that this is the case for plot 6 , where the growth of understory was unusually rapid.

It should be possible to retrospectively validate the historical patterns of LAI in these stands using available ground LAI data, the kind of relationships demonstrated here, and available Landsat TM imagery. Once the relationships between NDVI and LAI have been obtained, they could be extrapolated spatially with Landsat TM imagery and thus used to drive seasonally sensitive ecosystem models over a number of years (Gholz et al., 1990).

\section{CONCLUSION}

Landsat TM data were used to estimate the seasonal LAI of slash pine. This illustrates the potential value of remotely sensed data for the study of seasonal dynamics in forest canopies. 


\section{REFERENCES}

Ashcroft, P. M.; Catt, J. A.; Curran, P. J.; Munden, J.; and Webster, R.: The Relation Between Reflected Radiation and Yield on the Broadbalk Winter Wheat Experiment. Inter. J. Remote Sensing, 11 (in press), 1990.

Badhwar, G. D.; MacDonald, R. B.; and Mehta, N. C.: Satellite-Derived Leaf-Area-Index and Vegetation Maps as Input to Global Carbon Cycle Models-a Hierarchical Approach. Inter. J. Remote Sensing, vol. 7, 1986a, pp. 265-281.

Badhwar, G. D.; MacDonald, R. B.; Hall, F. G.; and Carnes, J. G.: Spectral Characterization of Biophysical Characteristics in a Boreal Forest: Relationship Between Thematic Mapper Band Reflectance and Leaf Area Index for Aspen. IEEE Trans. Geoscience and Remote Sensing, vol. 214, 1986b, pp. 322-326.

Chavez, P. S.: An Improved Dark-Object Subtraction Technique for Atmospheric Scattering Correction of Multispectral Data. Remote Sensing of Environ., vol. 24, 1988, pp. 459-479.

Chavez, P. S.: Radiometric Calibration of Landsat Thematic Mapper Multispectral Images. Photogrammetric Eng. and Remote Sensing, vol. 55, 1989, pp. 1289-1294.

Clark, B. P.: New Look-up Tables. EOSAT, Landsat Tech. Notes, vol. 1, 1986, pp. 2-8.

Curran, P. J.: Multispectral Remote Sensing for the Estimation of Green Leaf Area Index. Phil. Trans. Roy. Soc. London, Series A, vol. 309, 1983, pp. 257-270.

Curran, P. J.: Principles of Remote Sensing. Longman Scientific and Technical, London, 1985.

Curran, P. J.; and Williamson, H. D.: The Accuracy of Ground Data Used in Remote Sensing Investigations. Inter. J. Remote Sensing, vol. 6, 1985, pp. 1637-1651.

Curran, P. J.; and Williamson, H. D.: Airborne MSS to Estimate GLAI. Inter. J. Remote Sensing, vol. 8, 1987, pp. 57-74.

Danson, F. M.: Preliminary Evaluation of the Relationships Between SPOT-1 HRV Data and Forest Stand Parameters. Inter. J. Remote Sensing, vol. 8, 1987, pp. 1571-1575.

Fraser, R. S.; and Kaufman, Y. K.: The Relative Importance of Aerosol Scattering and Absorption in Remote Sensing. IEEE Trans. on Geoscience and Remote Sensing, vol. 23, 1985, pp. 625-633.

Gholz, H. L.; and Fisher, R. F.: Organic Matter Production and Distribution in Slash Pine (Pinus elliottii) Plantations. Ecology, vol. 63, 1982, pp. 1827-1839.

Gholz, H. L.; Fisher, R. F.; and Pritchett, W. L.: Nutrient Dynamics in Slash Pine Ecosystems. Ecology, vol. $66,1985 a$, pp. 647-659. 
Gholz, H. L.; Hendry, L. C.; and Cropper, W. P., Jr.: Organic Matter Dynamics of Pine Roots in Plantations of Slash Pine (Pinus elliottii) in North Florida. Canadian J. Forest Research, vol. 16, 1986, pp. 529-538.

Gholz, H. L.; Grier, C. C.; Campbell, A. G.; and Brown, A. T.: Equations for Estimating Biomass and Leaf Area of Plants in the Pacific Northwest. Forest Research Laboratory, Oregon State University, Corvallis Oregon, Research Paper 41, 1979.

Gholz, H. L.; Perry, C. S.; Cropper, W. P., Jr.; and Hendry L. C.: Litterfall, Decomposition, and Nitrogen and Phosphorus Dynamics in a Chronosequence of Slash Pine (Pinus elliottii) Plantations. Forest Science, vol. 31, 1985b, pp. 463-478.

Gholz, H. L.; Vogel, S. A.; Cropper, W. P., Jr.; McKelvey, K.; Ewel, K. C.; Teskey, R. O.; and Curran, P. J.: Dynamics of Canopy Structure and Light Interception in Pinus elliottii Stands of North Florida. Ecological Monographs (in press), 1990.

Girard, C. M.; Benoit, M.; deVaubernier, E.; and Curran, P. J.: SPOT HRV Data to Discriminate Grassland Quality. Inter. J. Remote Sensing 11 (in press), 1990.

Herwitz, S. R.; Peterson, D. L.; and Eastman, J. R.: Thematic Mapper Detection of Change in the Leaf Area Index of Closed Canopy Pine Plantations in Central Massachusetts. Remote Sensing of Environment (in press), 1990.

Holben, B. N.: Characteristics of Maximum Value Composite Images from Temporal AVHRR Data. Inter. J. Remote Sensing, vol. 7, 1986, pp. 1417-1434.

Jensen, J. R.: Biophysical Remote Sensing. Annals Assoc. American Geographers, vol. 73, 1983, pp. 111-132.

Jensen, J. R.; and Hodgson, M. E.: Remote Sensing of Forest Biomass: An Evaluation Using High Resolution Remote Sensor Data and Loblolly Pine Plots. The Prof. Geographer, vol. 37, 1985, pp. 46-56.

Johnson, J. D.: A Rapid Technique for Estimating Total Surface Area of Pine Needles. Forest Science, vol. 30, 1984, pp. 913-921.

Peterson, D. L.; Spanner, M. A.; Running, S. W.; and Teuber, K. B.: Relationship of Thematic Mapper Simulator Data to Leaf Area Index of Temperate Coniferous Forests. Remote Sensing of Environ., vol. 22, 1987, pp. 323-341.

Peterson, D. L.; and Running, S. W.: Applications in Forest Management. In Theory and Applications of Optical Remote Sensing (G. Asrar, Ed.), John Wiley, New York, 1989, pp. 429-473. 
Rook, D. A.; Grace, J. C.; Beets, P. N.; Whitehead, D.; Santantonio, D.; and Madgwick, H. A. I.: Forest Canopy Design: Biological Models and Management Implications. In Attributes of Trees as Crop Plants (M. G. R. Cannell and J. E. Jackson, Eds.), Institute of Terrestrial Ecology, Natural Environment Research Council, Huntingdon, United Kingdom, 1985, pp. 507-524.

Running, S. W.; Peterson, D. L.; Spanner, M. A.; and Teuber, K. B.: Remote Sensing of Coniferous Forest Leaf Area. Ecology, vol. 67, 1986, pp. 273-276.

Running, S. W.; Nemani, R. R.; Peterson, D. L.; Band, L. E.; Potts, D. F.; Pierce, L. L.; and Spanner, M. A.: Mapping Regional Forest Evapotranspiration and Photosynthesis by Coupling Satellite Data with Ecosystem Simulation. Ecology, vol. 70, 1989, pp. 1090-1101.

Sader, S. A.; Waide, R. B.; Lawrence, W. T.; and Joyce, A. T.: Tropical Forest Biomass Successional Age Class Relationships to a Vegetation Index Derived from Landsat TM Data. Remote Sensing of Environ., vol. 28, 1989, pp. 143-156.

Singh, S. M.: Simulation of Solar Zenith Angle Effect on Global Vegetation Index (GVI) Data. Inter. J. Remote Sensing, vol. 9, 1988, pp. 237-248.

Smolander, H.; Oker-Blom, P.; Ross, J.; Kellomaki, S.; and Lahti, T.: Photosynthesis of a Scots pine Shoot: Test of a Shoot Photosynthesis Model in a Direct Radiation Field. Agri. Forest Meteorology, vol. 38, 1987, pp. 231-242.

Spanner, M. A.; Pierce, L. L.; Peterson, D. L.; and Running, S. W.: Remote Sensing of Temperate Coniferous Forest Leaf Area Index: The Influence of Canopy Closure, Understory Vegetation and Background Reflectance. Inter. J. Remote Sensing, vol. 11, 1990, pp. 95-111.

Spanner, M. A.; Pierce, L. L.; Running S. W.; and Peterson, D. L.: The Seasonality of AVHRR Data of Temperate Coniferous Forests: Relationship with Leaf Area Index. Remote Sensing of Environment (in review).

U. S. Department of Agriculture: Soil Survey, Alachua County, Florida. U. S. Department of Agriculture, Washington, DC, 1954. 
Table 1. NDVI recorded by the Landsat Thematic Mapper and LAI for 16 plots on 3 dates. These data are expressed with two significant figures for ease of presentation here and are displayed as scatterplots in figure 3.

\begin{tabular}{cccccccc}
\hline $\begin{array}{c}\text { Plot } \\
\text { Number }\end{array}$ & $\begin{array}{c}\text { Treatment } \\
\text { C=Control }\end{array}$ & \multicolumn{2}{c}{ February 1988 } & \multicolumn{2}{c}{ September 1988 } & \multicolumn{2}{c}{ March 1989 } \\
& F=Fertilized & & & & & & \\
\hline 1 & F & 3.48 & 0.57 & 7.95 & 0.64 & 4.71 & 0.56 \\
2 & C & 2.93 & 0.53 & 4.55 & 0.57 & 2.77 & 0.51 \\
3 & C & 2.52 & 0.51 & 3.79 & 0.55 & 1.84 & 0.50 \\
4 & F & 3.16 & 0.56 & 6.91 & 0.65 & 3.88 & 0.57 \\
5 & C & 3.50 & 0.56 & 5.85 & 0.59 & 3.44 & 0.55 \\
6 & F & 3.42 & 0.56 & 7.78 & 0.64 & 4.63 & 0.61 \\
7 & C & 4.07 & 0.57 & 6.41 & 0.59 & 4.07 & 0.55 \\
8 & F & 3.97 & 0.59 & 9.24 & 0.64 & 5.50 & 0.61 \\
9 & C & 4.05 & 0.57 & 6.69 & 0.60 & 4.26 & 0.54 \\
10 & F & 3.27 & 0.56 & 7.28 & 0.64 & 3.99 & 0.56 \\
11 & F & 3.21 & 0.61 & 7.23 & 0.65 & 4.02 & 0.56 \\
12 & C & 3.73 & 0.57 & 6.12 & 0.58 & 3.89 & 0.55 \\
13 & C & 3.37 & 0.57 & 5.62 & 0.58 & 3.73 & 0.54 \\
14 & F & 3.32 & 0.60 & 7.60 & 0.64 & 4.30 & 0.57 \\
15 & F & 3.34 & 0.58 & 7.60 & 0.66 & 4.26 & 0.58 \\
16 & C & 3.18 & 0.56 & 5.14 & 0.58 & 2.88 & 0.52 \\
\hline
\end{tabular}

Table 2. Summary statistics for NDVI recorded by the Landsat Thematic Mapper and LAI for 16 plots on 3 dates.

\begin{tabular}{ccccccc}
\hline $\begin{array}{c}\text { Summary statistics } \\
\text { (Treatment C=Control }\end{array}$ & \multicolumn{2}{c}{ February 1988 } & \multicolumn{2}{c}{ Leptember 1988 } & \multicolumn{2}{c}{ March 1989 } \\
F=Fertilized) & & NDVI & LAI & NDVI & LAI & NDVI \\
\hline$X_{\text {total }}$ & 3.41 & 0.57 & 6.61 & 0.61 & 3.89 & 0.56 \\
$\bar{\sigma}_{\text {total }}$ & 0.39 & 0.02 & 1.35 & 0.03 & 0.83 & 0.03 \\
$\bar{X}_{c}$ & 3.41 & 0.56 & 5.52 & 0.58 & 3.36 & 0.53 \\
$\bar{\sigma}_{C}$ & 0.50 & 0.02 & 0.92 & 0.01 & 0.76 & 0.02 \\
$\bar{X}_{F}$ & 3.40 & 0.58 & 7.70 & 0.65 & 4.41 & 0.58 \\
$\bar{\sigma}_{F}$ & 0.24 & 0.02 & 0.66 & 0.01 & 0.50 & 0.02 \\
\hline
\end{tabular}


Table 3. Predictive regression relationships of the form LAI = a + b NDVI, for plots 1 to 16 on three dates. They were used to estimate the LAI values reported in table 4 and in figure 4.

\begin{tabular}{lccccc}
\hline \multicolumn{1}{c}{ Date } & $\mathrm{n}$ & $\mathrm{a}$ & $\mathrm{b}$ & $\begin{array}{c}\text { Standard error of } \\
\text { estimate (LAI) }\end{array}$ & $\mathrm{R}^{2}$ \\
\hline February 1988 & $\mathbf{8}$ & -14.31 & 32.25 & 0.33 & 0.86 \\
September 1988 & 8 & -20.02 & 43.62 & 0.82 & 0.82 \\
March 1989 & 8 & -10.80 & 26.29 & 0.52 & 0.83 \\
\hline
\end{tabular}

Table 4. Mean LAI for four fertilized and four control plots, over three dates, estimated from Landsat Thematic Mapper (TM) data (via three predictive regression relationships in table 3 ) and measured in the field.

\begin{tabular}{lcccc}
\hline \multirow{1}{*}{ Date } & \multicolumn{2}{c}{ Fertilized } & \multicolumn{2}{c}{ Control } \\
& $\begin{array}{c}\text { Landsat TM } \\
\text { estimate }\end{array}$ & $\begin{array}{c}\text { Field } \\
\text { measurement }\end{array}$ & $\begin{array}{c}\text { Landsat TM } \\
\text { estimate }\end{array}$ & $\begin{array}{c}\text { Field } \\
\text { measurement }\end{array}$ \\
\hline February 1988 & 4.60 & 3.42 & 3.95 & 3.81 \\
September 1988 & 8.24 & 7.43 & 5.16 & 5.90 \\
March 1989 & 4.12 & 4.14 & 3.33 & 3.69 \\
\hline
\end{tabular}




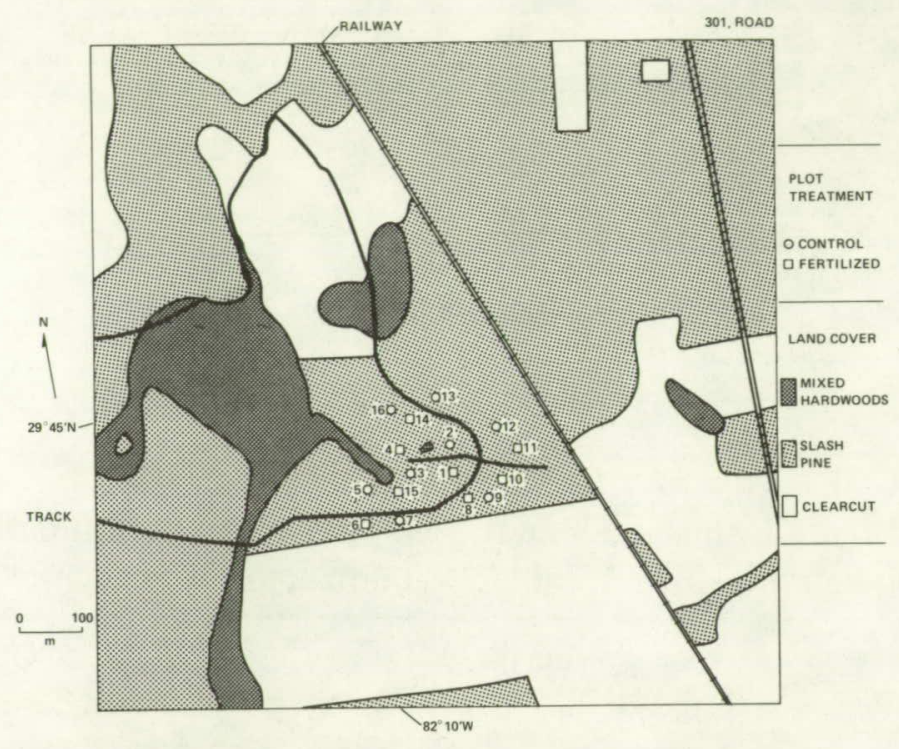

Figure 1. Sketch map of the study site in Florida. The Landsat Thematic Mapper images of this area are shown in figure 2. 


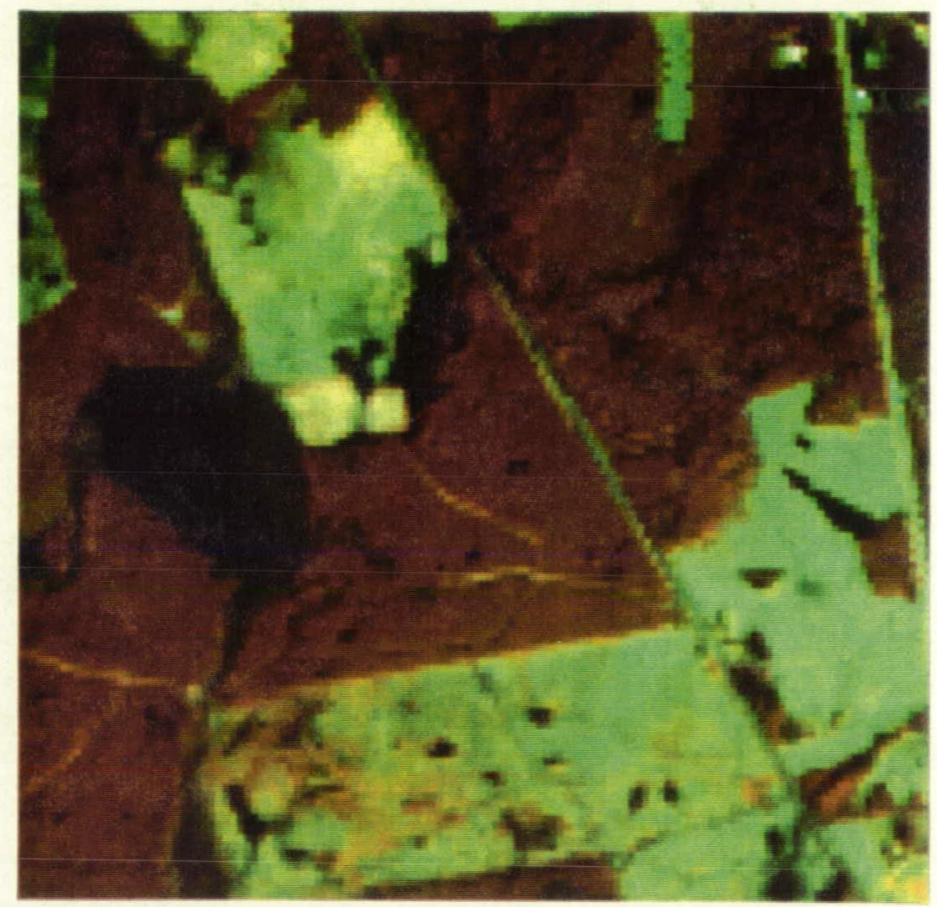

(a)

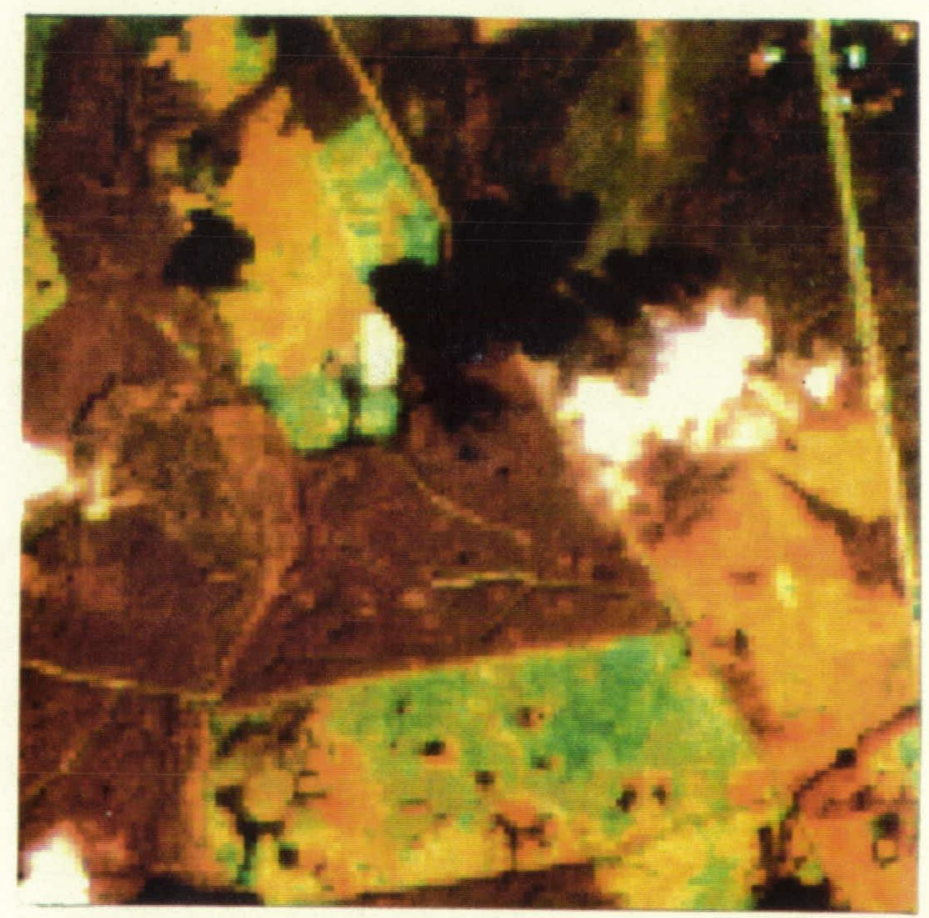

(b)

Figure 2. False color Landsat Thematic Mapper imagery covering approximately $3 \mathrm{~km} \times 3 \mathrm{~km}$ and centered on the study site (fig. 1). The imagery was recorded on three dates: (a) February 1988, (b) September 1988, and (c) March 1989. (See next page.) Note the cloud and cloud shadow on image (b). 


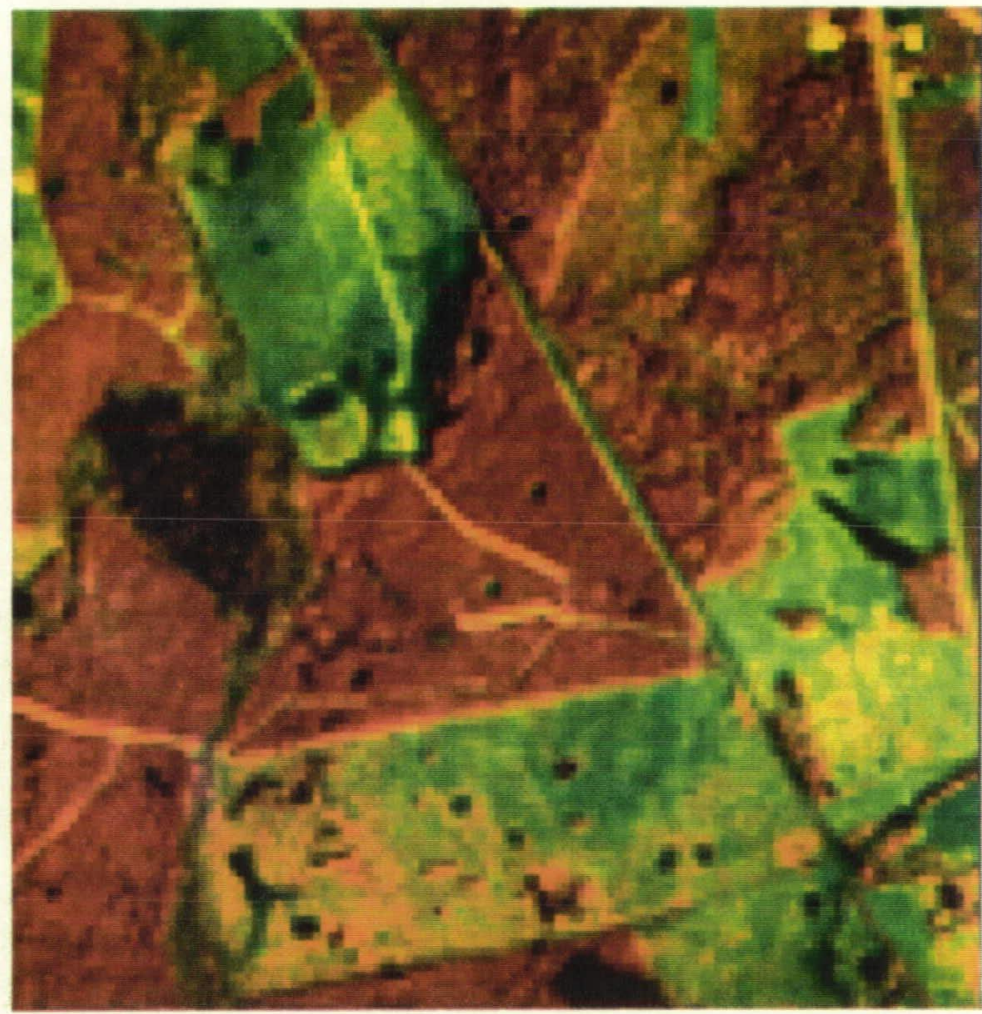

$$
\begin{aligned}
& \text { ORIGINAL PAGE } \\
& \text { COLOR PHOTOGRAPH }
\end{aligned}
$$

(c)

Figure 2. Concluded. 

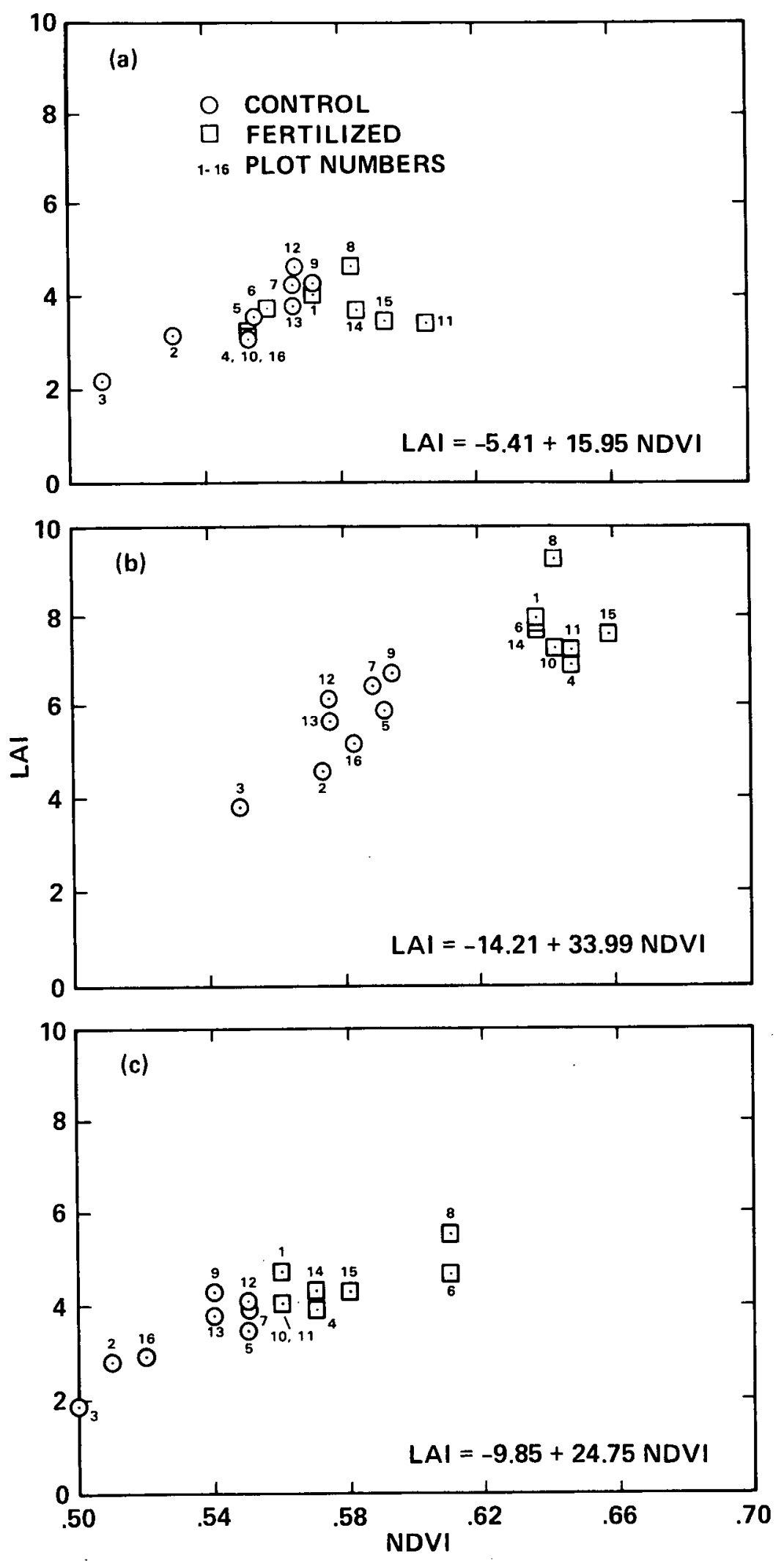

Figure 3. The relationship between NDVI recorded by the Landsat Thematic Mapper and LAI for 16 plots on 3 dates: (a) February 1988, (b) September 1988, and (c) March 1989. 


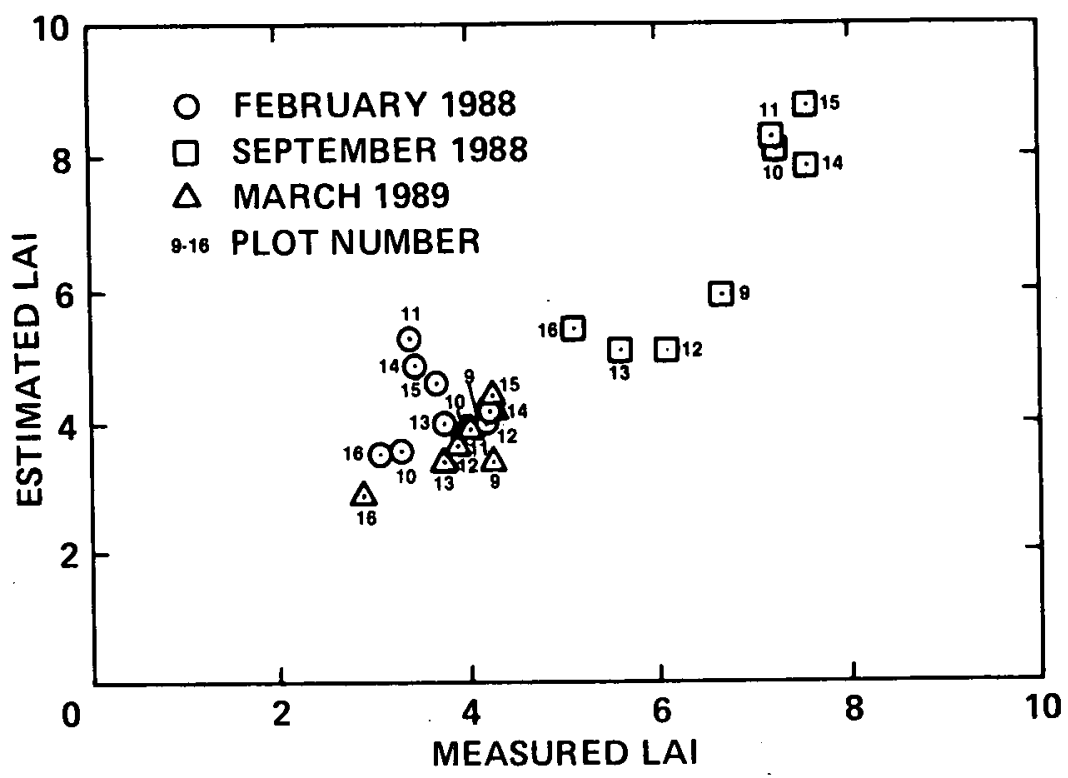

Figure 4. The relationship between the measured and estimated LAI for four control and four fertilized plots for three dates. The estimated LAI was derived using Landsat Thematic Mapper data and three predictive regression relationships, each based on data from four control and four fertilized plots (table 4). 

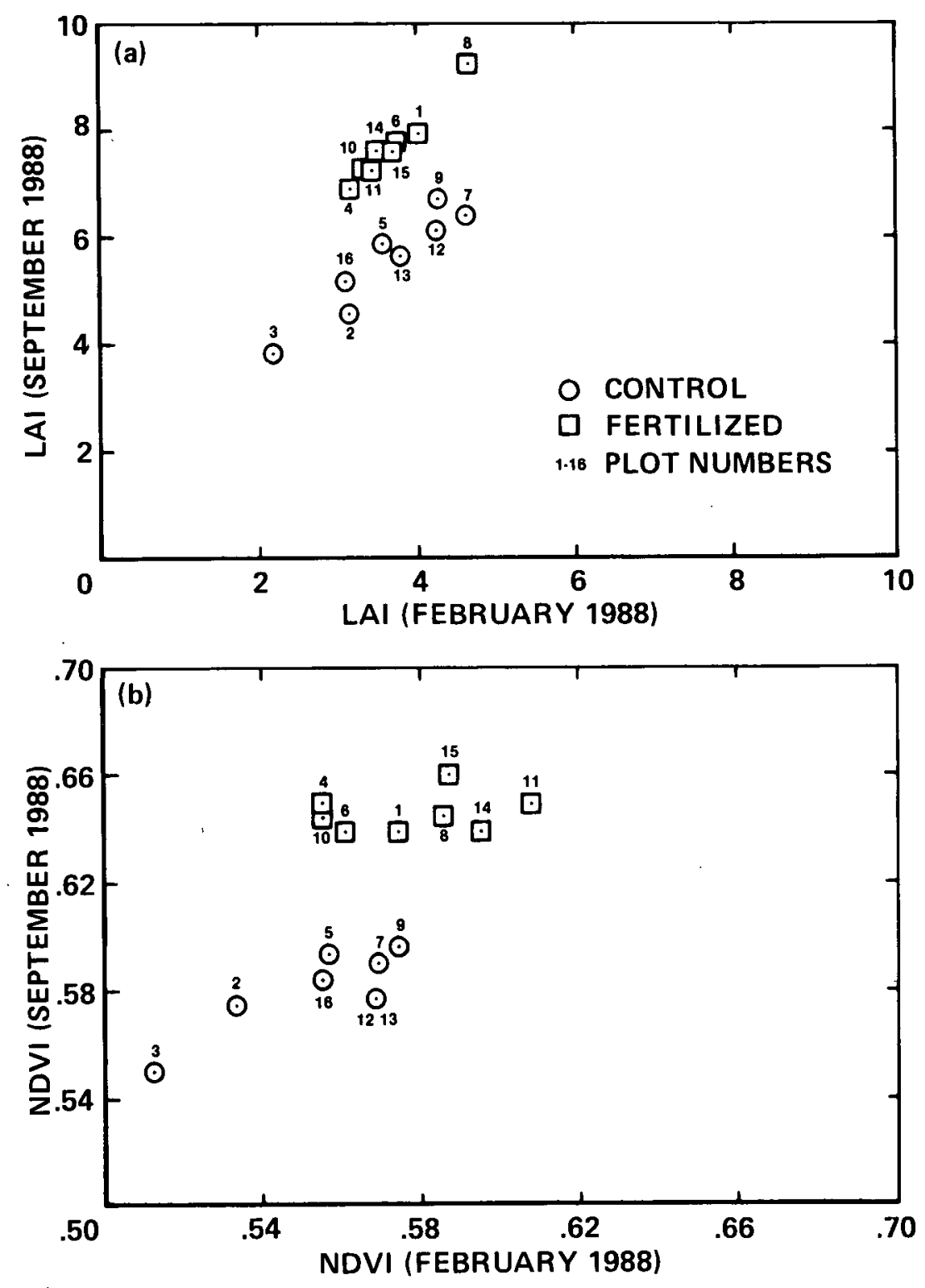

Figure 5. The relationship between (a) LAI measured in February 1988 and September 1988, and (b) NDVI recorded by the Landsat Thematic Mapper in February 1988 and September 1988. Note that in September 1988 the fertilized plots had a much larger LAI and NDVI than did the control plots and the LAI and NDVI values were much larger than in February 1988. 


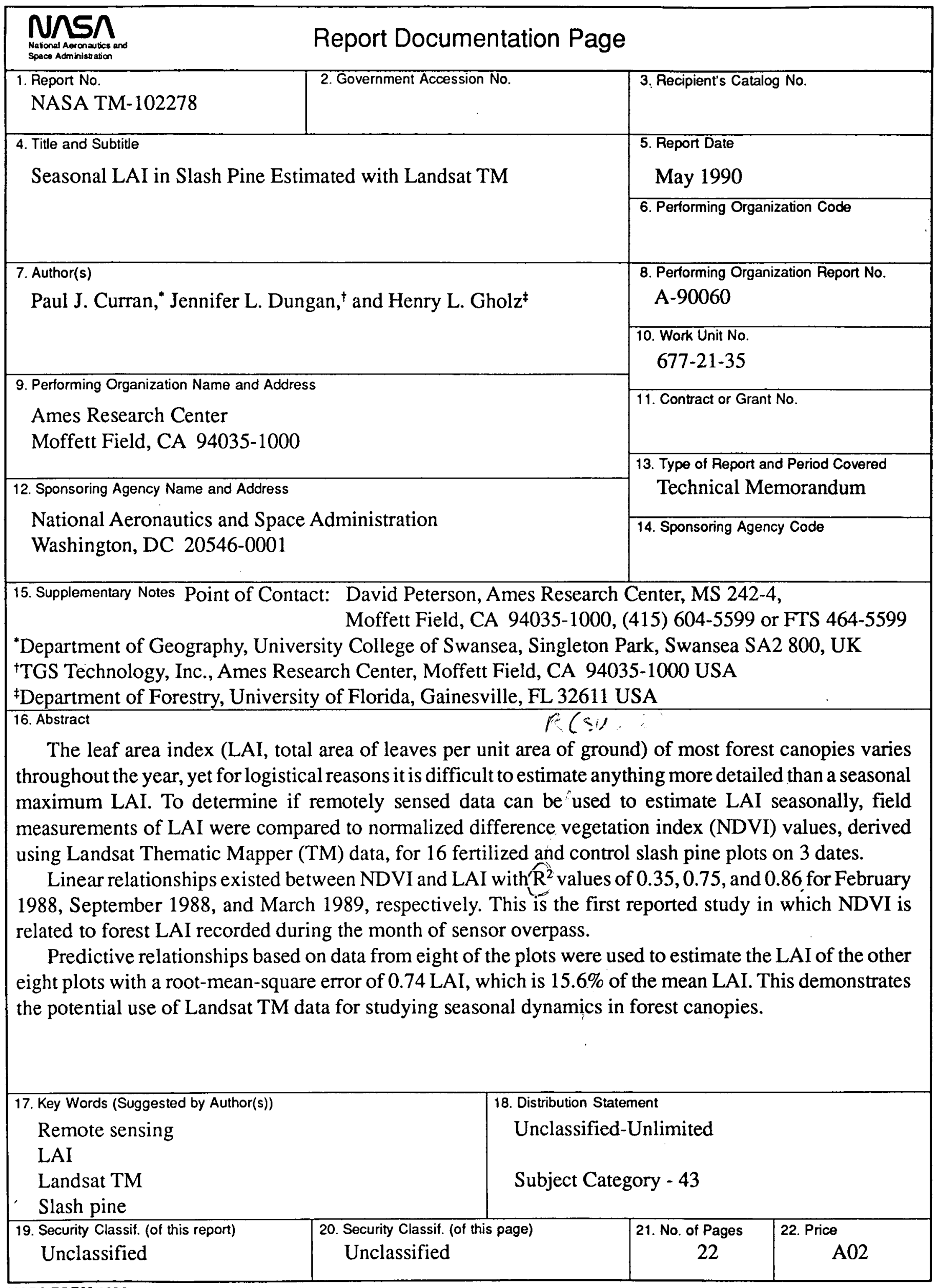

